\title{
Neues Set bietet Unterstützung bei der Patientenaufklärung
}

Therapiekonzepte, die auf die besonderen Bedürfnisse bestimmter Patientengruppen zugeschnitten sind, finden bei den Betroffenen in der Regel sehr großen Anklang. Dies ist auch bei MDI Mini-Dental-Implantaten von $3 \mathrm{M}$ ESPE der Fall, die sich speziell für die Prothesenstabilisierung bei älteren Patienten eignen. Um das Interesse der Patienten zu wecken, bedarf es jedoch einer konkreten Ansprache undAufklärung. Optimale Unterstützung dabei bietet ein neues Patientenmarketing-Set von $3 \mathrm{M}$ ESPE. Zunächst gilt es, Patienten durch gezielte Hinweise in und außerhalb der Praxis auf die minimalinvasive Therapieoption mit MDI Mini-Den-
tal-Implantaten aufmerksam zu machen. Dafür geeignet sind u. a. ein im Set enthaltener Thekenaufsteller sowie Bild- und Videomaterial, das sich beispielsweise auf der praxiseigenen Webseite verwenden lässt. Ist das Interesse einmal geweckt, sollte eine fundierte Aufklärung erfolgen. Speziell zu diesem Zweck wurde eine Powerpoint-Präsentation für Informationsveranstaltungen entwickelt: Erläutert werden wichtige Details beispielsweise zu den Vorteilen von Mini-Implantaten, der minimalinvasiven Vorgehensweise bei der Implantatinsertion sowie der Pflege. Alternativ eignen sich zur Erläuterung auch ein Ringbuch mit Be- schreibung des Behandlungsablaufs sowie Informationsbroschüren zur Weitergabe an die Patienten.

Bestellbar ist das Set für einen Beitrag von $49,95 €$ online unter www.3MESPEMDI-Webshop.de, wo registrierten Besuchern eine Auswahl an Vorlagen, Bild- und Videomaterial sogar kostenlos zum Download bereitgestellt wird,

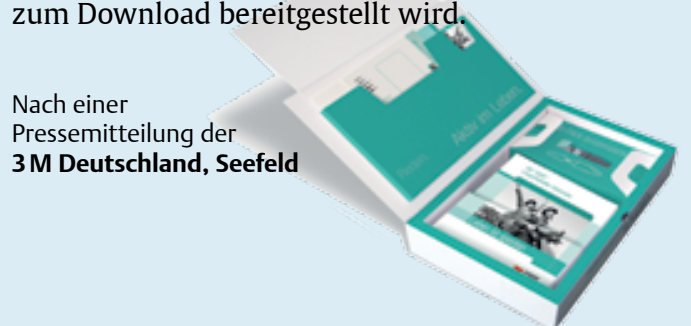

